\title{
Evaluation of immunoglobulin classes (IgA, IgG and IgM) levels and complement fixation activity in HIV infected subjects
}

\author{
M. IFEANYICHUKWU ${ }^{1 *}$, C.C. ONYENEKWE ${ }^{2}$, P.U. ELE ${ }^{3}$, N.K. UKIBE ${ }^{4}$, \\ S.C. MELUDU ${ }^{4}$, M.C. EZEANI ${ }^{1}$ and C.C. EZECHUKWU ${ }^{1}$ \\ ${ }^{I}$ Immunology Department, College of Health Sciences, Nnamdi Azikiwe University, Nnewi Campus, PMB 5001 \\ Nnewi, Anambra State, Nigeria. \\ ${ }^{2}$ Medical Laboratory Science Department, College of Health Sciences, Nnamdi Azikiwe University, Nnewi \\ Campus, PMB 5001 Nnewi, Anambra State, Nigeria. \\ ${ }^{3}$ Medicine Department, College of Health Sciences, Nnamdi Azikiwe University, Nnewi Campus, PMB 5001 \\ Nnewi, Anambra State, Nigeria. \\ ${ }^{4}$ Biochemistry Department, College of Health Sciences, Nnamdi Azikiwe University, Nnewi Campus, PMB \\ 5001 Nnewi, Anambra State, Nigeria. \\ *Corresponding author, E-mail: moifeanyi@yahoo.co.uk
}

\begin{abstract}
The study was designed to evaluate the immunoglobulin A, G and M levels and complement fixation activity in HIV infected participants, who were not administered antiretroviral therapy (ART). Eighty (80) HIV infected participants, aged between $15-55$ years ( $38 \pm 10$ years), were recruited for the study. Forty five (45) of the participants were classified as symptomatic HIV (stage ii), while the remaining 35 were classified as asymptomatic HIV (stage i). Similarly, 40 seronegative participants served as control. Blood samples were collected from the participants for the determination of HIV status by immunochromatography, HIV confirmation by Western blot, determination of immunoglobulin levels by immunoturbidimetry, and complement activity by complement fixation test. The IgG and $\operatorname{IgA}$ were significantly increased in symptomatic HIV infection compared with asymptomatic HIV infection $(\mathrm{p}<0.05)$. However, the value of $\operatorname{IgM}$ in asymptomatic and symptomatic HIV infected participants were similar $(p>0.05)$. The complement fixation activities decreased in HIV infected patients compared with the values in HIV seronegatives. The increase in IgA concentration with HIV infected participants may suggest existence of mucosal infections, while the increase in $\mathrm{IgG}$ concentration in HIV infected participants may suggest evidence of increased opportunistic infection requiring $\mathrm{IgG}$ response. The low level of complement activity in HIV infected participants may predispose individuals with HIV infection to disease commonly controlled through immunological activity of the complement.
\end{abstract}

(C) 2009 International Formulae Group. All rights reserved.

Keywords: Human Immunodeficiency Virus (HIV), immunoglobulins (IgA, IgG and IgM), complements.

\section{INTRODUCTION}

Two types of the HIV have been identified namely HIV-1 which is most prevalent causing global epidemic and HIV-2 which is more common in West Africa. The feature of the disease is immune suppression. There have been reports on the effect of HIV infections on several immunological parameters, and the correlation of these parameters with disease progression. Kashala et al. (1993) reported significantly elevated immunoglobulin levels amongst HIV positive individuals compared with HIV negative persons. In view of this report, the present 
study assessed the serum immunoglobulin A, $\mathrm{G} \& \mathrm{M}$ levels in HIV infected participants with emphasis on symptomatic (clinical stage ii) and asymptomatic (clinical stage i) states. Also, complement activation had been described in viral lysis, in both HIV infected adults (Perricone et al., 1987) and children (Jarvis et al., 1993). As a result of that, the present study also assessed the complement fixation ability of symptomatic HIV participants (stage ii) and asymptomatic HIV participants (stage i).

\section{MATERIALS AND METHODS}

Methods and selection of study population

A total of eighty (80) HIV infected patients were recruited for the study at the Voluntary Counselling and Testing (VCT) and HIV clinic of Nnamdi Azikiwe University Teaching Hospital Nnewi, Nigeria. They were aged 15-55 years $(38 \pm 1)$. Using the WHO classification for HIV infection and CD4 count, 45 of these patients were classified as symptomatic HIV (stage ii), while the remaining 35 were classified as asymptomatic HIV (stage i). Forty (40) apparently healthy HIV seronegative participants drawn from the student and staff population of Nnamdi Azikiwe University Teaching Hospital, Nnewi, Nigeria, served as control. Because of the life style it is unlikely that they may have been infected and that the result showed was not that of a window period. Five millilitres of blood was collected from the participants and dispensed into plain tubes for serum for immunoglobulins $\mathrm{A}, \mathrm{G}$ and $\mathrm{M}$ determination by immunoturbidimetry method, using Technicon Ames RA 50 Chemistry Analyzer, and complement fixation assay by complement fixation test. Informed consent was obtained from those who participated in the study. The Nnamdi Azikiwe University Teaching Hospital Board of Ethical Committee approved the study design.

Test for HIV Infection by Immmunochromatography as described by Manufacturers of the kit (Acon Laboratories Inc. USA)

Twenty five microlitres of serum samples was dispensed into the "specimen pad" of the test strip and $80 \mu \mathrm{l}$ of buffer was added. The reaction was allowed for 5 minutes, the appearance of distinct red lines at test region and control region of the kit suggest positive HIV test while one distinct red line in the region of the control suggest HIV seronegative test. The appearance of the distinct red line of the control region validates the result without which the kit is assumed to be non functional.

\section{HIV confirmatory test by Western Blot}

Two millimetres of the reconstituted phosphate buffer $\mathrm{pH} 8.6$ was added to the dish containing the nitrocellulose strip. The cells were incubated for 5 minutes at room temperature with slow shaking. Twenty microlitres of each patient's serum sample was added into the corresponding cell and incubated for 2 hours, at room temperature under slow shaking. The content of each dish was drained and each strip was washed twice for 5 minutes with $2 \mathrm{ml}$ of buffer. $2 \mathrm{ml}$ of enzyme linked anti IgG antibody was dispensed into each cell and incubated for 1 hour and 5 minutes at room temperature with shaking. Two millilitres of colour developing reagent (enzyme substrate) was dispensed into each cell after wasting. The colour reaction was stopped by removing reagent and washed 3 times with buffer as soon as the colour developed. The presence of shades of colour indicates positive results.

\section{Immunoglobulin classes (IgG, IgA, IgM) determination as described by manufacturers of the kit (Human Biochemica and Diagnostica Germany) Preparation of working calibrator}

Aliquot of immunoglobulin of known concentration (IgG, IgA, IgM), as calibrator was diluted with diluent (phosphate buffer $\mathrm{pH}$ 7.2) to obtain the following serial doubling dilutions; from 2 to 128.

\section{Preparation of serum samples}

Serum samples were diluted 1 in 21 with buffer, $\mathrm{pH} 7.2$ prior to estimation.

Analysis of immunoglobulins $($ Ig) using
Technicon Ames RA 50 Chemistry
Analyzer (Germany)
$50 \mu$ l standard solutions were aspirated into the Technicon, Ames RA 50 chemistry 
analyzer and programmed to produce calibrated curve for the standard solutions. Subsequently, each sample prepared was fed into the machine; the machine automatically estimates the concentration of the immunoglobulin in the sample with respect to the standard curve. The values of the immunoglobulin in the samples were digitally displayed.

\section{Complement fixation test}

One drop each of patient's serum and their serial doubling dilutions, guinea pigs complement (i.e. Minimum Haemolytic Dose) and the indicator cells (human red blood cell sensitized with anti D antibody) were mixed in precipitin tubes. The tubes were then incubated in the incubator at $37{ }^{\circ} \mathrm{C}$ for 2 hours. The titres of complement in the sera were determined by the highest dilution that is still showing haemolysis. Control HIV seronegative serum was processed following the same procedure.

\section{Statistical analysis}

The result of the analysis was statistically analyzed. Student's t-test and oneway analysis of variance (ANOVA) were used to compare means. The analyses were performed with the used of SPSS statistical software package. A $\mathrm{p}$ value of $<0.05$ was considered statistically significant.

\section{RESULTS}

\section{Serum immunoglobulin levels}

The mean $( \pm \mathrm{SD})$ serum $\mathrm{IgG}$ concentration $(\mathrm{mg} / \mathrm{dl})$ was significantly higher in both the symptomatic (10237.1 \pm 5796.4$)$ and asymptomatic (6238.6 \pm 3711.0$)$ HIV infected participants when compared with the corresponding values in control $(1716.5 \pm 415.4) \quad(p<0.05$ in each case $)$. Similarly, the mean $( \pm \mathrm{SD}) \operatorname{IgM}$ concentrations were significantly higher in the symptomatic (431.6 \pm 244.2$)$ and asymptomatic (316.0 \pm 204.2$) \quad$ HIV infected patients compared with the control (162.4 \pm 36.2$)$ $(\mathrm{p}<0.05)$. The mean $( \pm \mathrm{SD}) \operatorname{Ig} \mathrm{A}$ concentration was also significantly higher in the symptomatic $(375.3 \pm 178.7)$ and asymptomatic (293.1 \pm 96.6$)$ HIV infected patients compared with the control $(203.6 \pm 78.7)(p<0.05$ in each case) (Table 1).

The mean $( \pm \mathrm{SD})$ serum concentration of $\mathrm{IgG}$ was significantly higher in symptomatic (10237.1 \pm 5796.4$)$ HIV infected

Table 1: Mean $( \pm \mathrm{SD})$ serum levels of immunoglobulins $A, \mathrm{G}, \mathrm{M}(\mathrm{mg} / \mathrm{dl})$ and complement in HIV infected patients and control participants.

\begin{tabular}{|c|c|c|c|c|}
\hline & IgG (mg/dl) & IgA (mg/dl) & IgM (mg/dl) & Complement \\
\hline $\begin{array}{l}\text { Control } \\
(\mathrm{n}=40)\end{array}$ & $1716.5 \pm 415.4$ & $203.6 \pm 78.7$ & $162 . \pm 36.2$ & $16 \pm 00$ \\
\hline $\begin{array}{l}\text { Asymptomatic } \\
(\mathrm{n}=35)\end{array}$ & $6238.6 \pm 3711.0$ & $293.1 \pm 96.6$ & $316.0 \pm 204.2$ & $6.9 \pm 1.8$ \\
\hline $\begin{array}{l}\text { Symptomatic } \\
(n=45)\end{array}$ & $10237.1 \pm 5796.4$ & $375.3 \pm 178.7$ & $431.6 \pm 244.2$ & $7.3 \pm 1.5$ \\
\hline$f(p)$ & $26.8(.000)$ & $11.29(.000)$ & $12.26(.000)$ & $285.4(.000)$ \\
\hline $\mathrm{t}^{\mathrm{a}} \mathrm{p}^{\mathrm{a}}$ & $\mathrm{p}<001$ & $\mathrm{P}<0.01$ & $\mathrm{P}<0.01$ & $\mathrm{p}<0.01$ \\
\hline$t 1 p^{b}$ & $\mathrm{p}<0.01$ & $\mathrm{P}<0.01$ & $\mathrm{P}<0.01$ & $\mathrm{p}<0.01$ \\
\hline$t 1 p^{c}$ & $\mathrm{p}<0.01$ & $\mathrm{P}<0.05$ & $\mathrm{p}>0.05$ & $\mathrm{p}>.01$ \\
\hline
\end{tabular}


participants compared with asymptomatic HIV infected participants $(6238.6 \pm 3711.0)$ $(\mathrm{p}<0.01)$. Similarly, the mean $( \pm \mathrm{SD}) \operatorname{IgA}$ concentration in symptomatic HIV infected participants $(375.3 \pm 178.7)$ was significantly higher than corresponding value in the asymptomatic HIV infected participants (293.1+96.6) $(\mathrm{p}<0.05)($ Table 1).

However, no significant difference was observed in mean serum concentration of IgM between the symptomatic (431.6 \pm 244.2$)$ and asymptomatic $(316.0 \pm 204.2)$ HIV infected participants $(\mathrm{p}>0.05)$ (Table 1$)$.

The mean complement activity was significantly lower in both asymptomatic HIV infected participants (7.0 \pm 1.8$)$ and symptomatic HIV infected $(7.3 \pm 1.7)$ participants compared respectively with corresponding values in the controls $(16.0 \pm 0.1),(p<0.05$ in each case $)$. However, there was no significant difference in mean $( \pm \mathrm{SD})$ complement titre difference between the asymptomatic $(7.0 \pm 1.8)$ and symptomatic (7.3 \pm 1.7$)$ HIV infected participants $(p>0.05)$.

\section{DISCUSSION}

\section{Immunoglobulin G, M and A levels}

The study observed increased IgG and IgA concentrations amongst HIV infected symptomatic and asymptomatic participants. This was not the case for the serum IgM. The observed increase in serum $\operatorname{IgG}$ and $\operatorname{IgA}$ suggest the involvement of these classes of immunoglobulin in possible protective immunity. This indicative since there was obvious class switching in favour of $\operatorname{IgG}$ and IgA. It may also be an indication for existing opportunistic agents provoking this type of immunological response.

The high increases in serum $\operatorname{IgG}$ concentration with disease progression suggest the extent of super antigen interaction with the humoral immune cells and effective immunoglobulin switching. This observed increase in $\mathrm{IgG}$ concentration is in agreement with report of Arinla and Igbi (1998) and Orinaasen et al. (2004) who observed that increase in $\mathrm{IgG}$ concentration correlated well with disease progression amongst HIV infected patients.

This study also revealed a significant increase in $\operatorname{IgA}$ concentration in HIV infected participants. $\operatorname{IgA}$ is a secretory immunoglobulin and common viral infection starts with local invasion of epithelial surface, which initially induces the production of secretary IgA from these surfaces. Roitt et al. (2003) and Broliden (2001) reported that resistance to HIV infection in exposed seronegative persons involved HIV-specific mucosal and systemic immune responses. The increase in $\operatorname{IgA}$ concentration in HIV infection, however, clearly means that there was increased involvement of IgA in mucosal and submucosal immune defence mechanism. This may likely be the case since the serum IgM concentration was not affected.

The study showed increase in IgM concentration in HIV seropositive participants compared with the HIV negative healthy controls. However, the IgM values remain similar between asymptomatic (clinical stage i) and symptomatic (clinical stage ii) participants. The above pattern of $\operatorname{IgM}$ concentration in HIV infection may be attributed to challenge and activation of mature B cells by HIV antigens, which initially produce a relatively non-specific IgM. Thus, it could be that HIV infection present different pattern of antibody response depending on the stage of the disease.

Complement activation had been described in viral lysis, in both HIV - infected adults (Perricone et al., 1987) and children (Jarvis et al., 1993). The complement activities as part of the non-specific humoral immune mediation in HIV infection appear early in HIV infection (Mcknight et al., 1997; Aasa-Chapman et al., 2004). However, AasaChapman et al. (2004) show that IgG antibodies to HIV envelop can lyse viruses through the classical pathway of complement activation. The study has found significant reduced complement levels in both the asymptomatic (clinical stage i) and symptomatic (clinical stage ii) HIV infected patients compared with the HIV seronegative controls as was also reported by earlier workers (Perricone et al., 1987; Jarvis et al., 1993).

Low level of complement found in HIV infection had been attributed to complement consumption by c1q-bound immune complexes (Jarvis et al., 1993), and indeed, 
significant elevated levels of circulating immune complexes had been reported in HIV-infected patients in Ibadan (Onyenekwe et al., 2006).

The circulating immune complexes (CIC), bind clq, causing high activation of complement in the system. The initial high activation of complement may lead to depletion of complement components, which subsequently results in diminished fixation activities in the host. The resultant effect is deposition of circulating immune complexes.

Besides, inducing direct lysis of pathogens, the complement system also has opsonizing, phagocytic - inducing chemo attractant and immune stimulatory function (Blue et al., 2004). Specific antibodies alone cannot effectively neutralize many viruses, but complement activation can enhance the antiviral effects of antibodies by opsonizing virons or inducing lysis of the particles (Blue et al., 2004).

The decline in complement activity in HIV infection observed in this work suggests that complement mediated immune intervention may be lowered or negligible as they may have been grossly consumed. The finding in this study leads us also to conclude that, complement consumption seem to be an early finding in HIV infection since it was noticed even in asymptomatic HIV patients.

\section{REFERENCES}

Aasa-Chapman MMI, Hayman A, Newton P, cornforth D, Williams I, Borrow P, Balfe P, Meknight A. 2004. Development of the antibody response in acute HIV-1 infection. AIDS, 18: $371-381$.

Blue CE, Spiller B, Blackbourn. 2004. The relevance of complement to virus biology. Virology, 319: 176 - 184.

Broliden K, Hinkala J, Devito C. 2001. Functional HIV-1 specific IgA antibodies in HIV-1 exposed, persistently IgG seronegative female sex workers. Immunol. Lett., 79: 29-36.

Jarvis JN, Taylor H, Lobidze M, Dejonge J, Chang S, Cohen F. 1993. Complement activation and rheumatoid factor expression in children congenitally infected with human immunodeficiency virus. Clin. Immunol. Immunopathol., 67: 50-54.

Kashala O, Kayembe K, Kanki P, Diese M, Kalengayi M, Izzia KW, Essex M. 1993. Humoral aspects of anti-HIV immune responses in Zairians with AIDS: lower antigenemia does not correlate with immune complexes level. AIDS Res. Hum. Retroviruses, 9(3): 351-358.

Mcknight A, Wilkinson D, Simmons G. 1997. Inhibition of human immunodeficiency virus fusion by monoclonal antibody to a co-receptor (cxce4) is both cell type and virus strain dependent. J. Virol., 71: 1692-1696.

Onyenekwe CC, Ezeugwunne IP, Meludu SC, Ilika A, Igwegbe AO, Ukibe RN, Onochie AU. 2006. Urinary ascorbic acid and serum concentration of circulating immune complexes and albumin in HIV infected subjects. Journal of Biomedical Investigation, 4(2): 54 - 59.

Orinaasen V, Bruun J, Awor AC, Ulvestad E. 2004. Immunoglobulin levels Amongst persons with and without Human Immunodeficiency virus type 1 infection in Uganda and Norway. San. J. Immunol., 59: $203-208$.

Perricone R, Fontana L, De Carolis C, Carini C, Siriani MC, Aiuti F. 1987. Evidence for activitaion of complement in patients with AIDS related complex (ARC) and for lymphoadenopathy synchrome (LAS). Clin. Exp. Immunol., 70: 500-507.

Roitt 1, Brostotte I, Male D. 2003. Immunology (2nd edn). Gower Medical Publishing: England; 8.1-8.6. 